\title{
Safety and efficacy of afatinib as add-on to standard therapy of gemcitabine/cisplatin in chemotherapy-naive patients with advanced biliary tract cancer: an open- label, phase I trial with an extensive biomarker program
}

Markus Moehler ${ }^{1,2^{*}}$, Annett Maderer ${ }^{1}$, Anne Ehrlich², Friedrich Foerster ${ }^{1}$, Arno Schad ${ }^{3}$, Tanja Nickolay², Christian Ruckes², Arndt Weinmann', Visvakanth Sivanathan', Jens U. Marquardt', Peter Robert Galle1, Marcus Woerns ${ }^{1,4}$ and Thomas Thomaidis ${ }^{1}$ (i)

\begin{abstract}
Background: To date, the cornerstone of treatment in patients with advanced or metastatic cholangiocarcinoma (CCA) is systemic chemotherapy based on a combination of gemcitabine and a platinum derivative. Other therapeutic approaches including targeted agents and tyrosine kinase inhibitors (TKI) have demonstrated disappointing results, highlighting the complexity of CCA. Recently, drugs aiming at the inhibition of HERreceptors have shown first therapeutic benefit in patients with late stage disease.

The aim of this phase I study was to test the dose level toxicities (DLTS), safety and efficacy of afatinib, a highly specific panErbB family receptor TKI, in chemotherapy naive patients with advanced CCA in conjunction with an extensive biomarker program.
\end{abstract}

Methods: Afatinib was administered continuously p. o. as add-on in patients with advanced CCA who received conventional chemotherapy with gemcitabine/cisplatin. A classical $3+3$ phase I study was employed, while the maximum tolerated dose (MTD) of oral afatinib was determined in a 2 step dose escalation. Safety, overall survival (OS) and progression free survival (PFS) were evaluated for all patients. Finally, a translational biomarker analysis was conducted for the EGFR and VEGF signalling cascades.

Results: Overall, 9 patients were enrolled. Further recruitment was discontinued due to lack of efficacy results of the tested drug in other indications.

$30 \mathrm{mg}$ afatinib could be safely administered as add-on to $80 \%$ of standard dose gemcitabine/cisplatin. The mOS and mPFS were 7.7 and 6.0 months, respectively. Diarrhoea and haematological disorders were the most common observed AEs. Almost all patients overexpressed EGFR on their tumour tissues, whereas none of them expressed mutations in Exons 18, 19 and 21. Non-responders showed a higher variation of VEGF-C, $-D$, leptin and sEGFR in their (Continued on next page)

\footnotetext{
* Correspondence: moehler@mail.uni-mainz.de; thomaidi@uni-mainz.de

'I. Medical Department, Johannes-Gutenberg University, Mainz, Germany

${ }^{2}$ Interdisciplinary Center for Clinical Trials, Johannes-Gutenberg University of

Mainz, Mainz, Germany

Full list of author information is available at the end of the article
}

(c) The Author(s). 2019 Open Access This article is distributed under the terms of the Creative Commons Attribution 4.0 International License (http://creativecommons.org/licenses/by/4.0/), which permits unrestricted use, distribution, and reproduction in any medium, provided you give appropriate credit to the original author(s) and the source, provide a link to the Creative Commons license, and indicate if changes were made. The Creative Commons Public Domain Dedication waiver (http://creativecommons.org/publicdomain/zero/1.0/) applies to the data made available in this article, unless otherwise stated. 
(Continued from previous page)

sera.

Conclusions: Afatinib failed to show survival benefits in combination with gemcitabine/cisplatin in patients with advanced CCA. Mutational analysis of EGFR and pathways associated with VEGF-C, $-D$ and leptin might show promising results in future studies.

Clinical trials registration: NCT01679405 August, 2012.

Keywords: Cholangiocarcinoma, Afatinib, BIBW 2992, Biomarkers, EGFR, panHER inhibition

\section{Background}

Cholangiocarcinoma (CCA) is the second most common primary liver cancer after hepatocellular carcinoma (HCC) and is characterized by poor prognosis and limited treatment options. Due to the lack of characteristic symptoms, most patients present with advanced-stage disease $[1,2]$ resulting in a median survival time (mOS) of about six months $[3,4]$.

Surgical resection remains the only curative treatment for CCA. However, 5-year survival rates vary from 8 to $47 \%$ for intrahepatic (iCCA) and $20-54 \%$ for extrahepatic (eCCA) biliary cancer due to recurrent or metastatic disease $[5,6]$. In patients with advanced, unresectable CCA, systemic chemotherapy has been shown to extend survival compared to best supportive care (BSC). The phase III UK ABC-02 study has established the gemcitabine/cisplatin (gem/cis) combination as a standard of care in these patients [7]. Taking into consideration that the mOS under the current standard regimen is $<1$ year [7], new therapeutic approaches for advanced CCA are greatly needed.

The HER family receptors (EGFR/HER1, HER2neu, HER3 and HER4) are associated with increased cellular proliferation, angiogenesis and loss of apoptosis by activation of a complex pathway network including the MAPK kinase cascade, P13K/ATK pathway and STAT transcription factors $[8,9]$. A synergy between these receptors - via heterodimerization and cross-linking has been proposed as a mechanism of resistance to single HER inhibitors, suggesting that ErbB family inhibition may overcome the shortcoming of single targeted therapies. In this context, ErbB family inhibitors such as AC480, HM781-36B, HKI-272 and dacomitinib have demonstrated promising results in phase I/II studies in patients with advanced solid tumours [10-12].

The anilino-quinazoline derivative BIBW 2992 (Afatinib, Gilotrif ${ }^{\circ}$ ), is an oral, highly specific, irreversible panErbB family (EGFR, HER2neu, HER4) receptor TKI already approved by the Food and Drug Administration (FDA) and the European Medicines Agency (EMA) for the treatment of non-small-cell lung cancer (NSCLC) [13]. In preclinical animal models, afatinib was safely combined with a variety of chemotherapeutic agents, including paclitaxel, gemcitabine and cisplatin with no significantly increased toxicity [14]. Combination chemotherapy with gemcitabine was also investigated in the Mia-PaCa-2 human pancreatic tumour model [15]. Administration of afatinib did not diminish the efficacy of gemcitabine, but revealed additive anti-tumour activity in this preclinical model of human pancreatic carcinoma [15]. Furthermore, afatinib already demonstrated good tolerability and efficacy as monotherapy in patients with advanced colorectal and esophageal cancer $[16,17]$.

The aim of this phase I trial was to assess the dose-limiting toxicities (DLTs), the maximum tolerated dose (MTD) as well as the efficacy of afatinib combined with gem/cis in chemotherapy naive patients with advanced CCA. Furthermore, we conducted a thorough translational research analysis of the epidermal growth factor receptor (EGFR) and vascular endothelial growth factor (VEGF) associated cascades to search to identify additional biomarker candidates for further development.

\section{Methods}

\section{Patients and study design}

This was an open-label, uncontrolled phase I trial with a 3 +3 design evaluating the safety and toxicity as well as the anti-tumour activity of afatinib given as add-on to the combination therapy of gem/cis in chemotherapy naive patients with advanced or metastatic CCA. The investigator-initiated study was conducted at the University Medical Center of the Johannes-Gutenberg University Mainz, Germany. Patients' enrolment period was 2 years, whereas the last recruited patient began treatment in August 2014. Patients' inclusion and exclusion criteria are provided as supporting information (Additional file 1: Table S1).

The study was performed in accordance with the provisions of the Declaration of Helsinki, International Conference on Harmonisation, and Good Clinical Practice guidelines (NCT01679405). All patients provided written informed consent before enrolment.

\section{Treatment and dose-escalation protocol}

The MTD of oral afatinib was evaluated in a 2 step dose escalation. The MTD was defined as the highest dose level (DL) at which $<33 \%$ of patients experienced a dose-limiting toxicity (DLT, Additional file 2: Table S2). $\mathrm{Gem} / \mathrm{cis}$ was administered in three week cycles with 
treatment on day 1 and 8 , respectively, whereas afatinib tablets were administered orally continuously $(20 \mathrm{mg}, 30$ $\mathrm{mg}$ or $40 \mathrm{mg}$ once daily). In part B of the study it was originally planned to have an expansion cohort with the inclusion of up to seven further patients.

A standard $3+3$, phase I methodology was employed for each regimen, with three patients being treated at the initial dose (dose level 1). If no DLT was observed within the first cycle in any of these patients, then the dose was escalated to dose level 2 and three more patients were treated. If one patient experienced a DLT, another three patients were treated at the same dose level. In the event that two or more patients experienced a DLT, a dose de-escalation was initiated.

Dose Level 1: $30 \mathrm{mg}$ afatinib, gemcitabine $\left(1.000 \mathrm{mg} / \mathrm{m}^{2} \mathrm{i}\right.$. v.)/cisplatin (25 mg/m ${ }^{2}$ i. v.), Dose Level 2: $40 \mathrm{mg}$ afatinib, gemcitabine $\left(1.000 \mathrm{mg} / \mathrm{m}^{2}\right.$ i. v.)/cisplatin $\left(25 \mathrm{mg} / \mathrm{m}^{2}\right.$ i. v.), Dose Level - 1: $30 \mathrm{mg}$ afatinib, gemcitabine $\left(800 \mathrm{mg} / \mathrm{m}^{2} \mathrm{i}\right.$. v.)/cisplatin (20 mg/m² $\mathrm{m}$. v.), Dose Level - 2: $20 \mathrm{mg}$ afatinib, gemcitabine $\left(800 \mathrm{mg} / \mathrm{m}^{2}\right.$ i. v. $) /$ cisplatin $\left(20 \mathrm{mg} / \mathrm{m}^{2}\right.$ i. v.).

Tumour measurements were done at screening (within day -30 and day -1) and subsequently after the second, fourth, sixth and eighth cycle, respectively.

The treatment continued until development of progressive disease according to RECIST 1.1 [18], intolerable toxicity according to the DLT definitions, patient's decision to discontinue therapy, or up to a maximum of 8 cycles of treatment.

The follow up period was set to 12 months.

Safety was evaluated by the assessment of adverse events (AEs), clinical laboratory tests, vital signs, physical examinations and cardiac function.

\section{Translational research analysis Immunohistochemistry}

Eight of 9 paraffin embedded tissue blocks were available for analysis. Expression of EGFR, HER2neu, HER3, and HER4 were analysed by immunochemistry (IHC).

Three $\mu \mathrm{m}$ thick tissue sections were cut and mounted on super frost slides. These were deparaffinized, rehydrated and peroxidase blocked $\left(3 \% \mathrm{H}_{2} \mathrm{O}_{2}\right.$ in methanol, 30 min). Staining was performed on a DAKO autostainer with required staining kits (DAKO) according to the manufacturers' instructions. Slides were incubated with the respective primary antibodies for EGFR (Clone 2-18C9, DAKO, rtu), HER2neu (polyclonal, DAKO, rtu), HER3 (Clone SP-71, Zytomed, 1:100) and HER4 (polyclonal, Zytomed, 1:50). The staining was evaluated by two independent, blinded investigators as recommended by the manufacture guidelines for membrane staining (DAKO).

\section{EGFR mutation analysis}

EGFR mutations were analysed in exons 18, 19 and 21 of the EGFR gene after microdissection of FFPE specimens, followed by allele discriminating PCR and Sanger sequencing, according to the manufacturer's protocol.

\section{Enzyme-linked immunosorbent assay (ELISA)}

Serum samples of all 9 patients at each cycle on day one were collected and analysed by duo set ELISAs (R\&D) for VEGF-A, -C, -D, sEGFR and Hif1 $\alpha$ as well as by customized multiplex ELISAs (eBioscience) for EGF, FGF-2, GITR, GTRL, HGF, Leptin, PD-L1, LAG3, VEGF-A and SDF1 $\alpha$ on the Bio-Plex MAGPIX System, Bio-Rad. All ELISAs were performed according to the manufacturer's instructions.

\section{Statistical analysis}

Biometrical analyses were predefined in the study protocol and its statistical exploration plan was finalized and authorized before start of the clinical trial. The main analysis population was the safety population comprising all patients who received at least one dose of trial treatment. Dose justifications were done according to clinical assessment. For survival parameters including overall survival and time to progression, Kaplan-Meier plots and estimates are presented. Tumour control rates are presented by absolute and relative frequencies.

Due to the small number of patients, descriptive analysis of association between the results of immunohistochemistry, ELISA and clinical-pathological parameters were performed. Comparisons of sera levels and observed changes during therapy were evaluated by Mann Whitney U test.

\section{Results}

\section{Patient characteristics}

A total of 9 patients (pts) were enrolled, of which 3 patients were treated with dose level 1 and 6 patients with dose level -1 . All patients were Caucasians. The median age was 60 years (38-80), and 4 patients $(44 \%)$ were female (Table 1). 4/5 patients were ECOG 0/1 across dose levels 1 and -1 , respectively. The most common reasons for trial discontinuation were disease progression $(n=5$, $56 \%)$, and $\mathrm{AE}(n=3,33 \%)$.

Six patients had their primary tumour in the liver, whereas three of them had eCCA. All tumours metastasized and were of grade 2 or 3 .

The target lesions were located most frequently in the liver ( 6 lesions in 6 pts), in mesenterial nodes (2 lesions in 2 pts) and in the lung (4 lesions in 2 pts). The median size of target lesions was $28 \mathrm{~mm}$ and ranged from 11 $\mathrm{mm}$ to $202 \mathrm{~mm}$. All patients had non-target lesions; they were located most frequently in the liver (7 pts), the lung (7 pts) and in lymph nodes (6 pts. other lymph nodes, 1 pts. lymph nodes of hepatic portal, data not shown). 
Table 1 Patients' demographics

\begin{tabular}{|c|c|c|c|}
\hline Variable & $\begin{array}{l}\text { Dose level } 1 \\
(N=3)\end{array}$ & $\begin{array}{l}\text { Dose level - } 1 \\
(N=6)\end{array}$ & $\begin{array}{l}\text { Total } \\
(N=9)\end{array}$ \\
\hline \multicolumn{4}{|l|}{ Age [Years] } \\
\hline$N$ & 3 & 6 & 9 \\
\hline Mean (SD) & $62.00(21.63)$ & $60.17(7.31)$ & $60.78(12.30)$ \\
\hline Min & 38.0 & 51.0 & 38.0 \\
\hline Median & 68.00 & 59.00 & 60.00 \\
\hline Max & 80.0 & 71.0 & 80.0 \\
\hline Missing & 0 & 0 & 0 \\
\hline \multicolumn{4}{|l|}{ Gender } \\
\hline Female & $1(33.33 \%)$ & $3(50.00 \%)$ & $4(44.44 \%)$ \\
\hline Male & $2(66.67 \%)$ & $3(50.00 \%)$ & $5(55.56 \%)$ \\
\hline \multicolumn{4}{|l|}{ Ethnicity } \\
\hline Caucasian & $3(100.00 \%)$ & $6(100.00 \%)$ & $9(100.00 \%)$ \\
\hline \multicolumn{4}{|l|}{ Primary tumour } \\
\hline Intrahepathic tumour & $3(100.00 \%)$ & $3(50.00 \%)$ & $6(66.67 \%)$ \\
\hline Extrahepatic tumour & $0(0.00 \%)$ & $3(50.00 \%)$ & $3(33.33 \%)$ \\
\hline \multicolumn{4}{|l|}{ ECOG } \\
\hline 0 & $2(66.67 \%)$ & $2(33.33 \%)$ & $4(44.44 \%)$ \\
\hline 1 & $1(33.33 \%)$ & $4(66.67 \%)$ & $5(55.56 \%)$ \\
\hline Metastatic disease & $3(100.00 \%)$ & $6(100.00 \%)$ & $9(100.00 \%)$ \\
\hline \multicolumn{4}{|l|}{ Target lesions } \\
\hline Primary tumour & 1 (14.29\%) & $1(10.00 \%)$ & $2(11.76 \%)$ \\
\hline Liver & $3(42.86 \%)$ & $3(30.00 \%)$ & $6(35.29 \%)$ \\
\hline Lung & $2(28.57 \%)$ & $2(20.00 \%)$ & $4(23.53 \%)$ \\
\hline Other lymph nodes & $1(14.29 \%)$ & $0(0.00 \%)$ & $1(5.88 \%)$ \\
\hline Peritoneum & $0(0.00 \%)$ & $1(10.00 \%)$ & $1(5.88 \%)$ \\
\hline Soft tissues & $0(0.00 \%)$ & $1(10.00 \%)$ & $1(5.88 \%)$ \\
\hline Others & $0(0.00 \%)$ & $2(20.00 \%)$ & $2(11.76 \%)$ \\
\hline
\end{tabular}

SD Standard Deviation

\section{Treatment exposure}

Study treatment started with three patients in dose level 1. Two of them showed disease progression and stopped study treatment during cycle 7 . One patient discontinued treatment due to AEs and did not re-start study treatment, because the interruption lasted longer than allowed by the protocol. Since DLTs appeared in all three patients in dose level 1 , the coordinating investigator of the clinical trial decided to decrease the dose of $\mathrm{gem} /$ cis proceeding with dose level -1 .

In dose level - 1, diarrhoea and thrombocytopenia occurred in only one patient, therefore three more patients were further treated with the same dose. DLT occurred finally in one out of six patients, and therefore this dose level was defined as the MTD.

In two out of six patients, afatinib dose was reduced to $20 \mathrm{mg}$ per day due to AEs. Two out of six patients in dose level-1 discontinued treatment due to disease progression. In another patient disease progression was stated at the end of cycle 8 . Two patients discontinued due to AEs.

In summary, the mean number of treatment cycles was 4.78 (SD 2.68) with a mean duration of 3.6 months (SD 2.2 months) and a mean number of afatinib doses of 100.89 (SD 60.57, Table 2). The average gemcitabine and cisplatin doses were $797.11 \mathrm{mg} / \mathrm{m}^{2}$ (SD 157.31) and $19.89 \mathrm{mg} / \mathrm{m}^{2}$ (SD 3.79), respectively.

\section{Efficacy}

No complete response (CR) and no partial response (PR) according to RECIST 1.1 were observed throughout the study. Four patients had stable disease at the end of treatment and five patients experienced stable disease as the best tumour control. The mOS was 7.7 months (95\% CI: 2.5 to 15 Fig. 1) and the median time to progression (mPFS) was 6.0 months (95\% CI: 1.6 to 11, Fig. 2). mPFS was defined as the time from start of treatment to first documentation of objective tumour progression according to RECIST 1.1 or a bilirubin level higher than $6 \mathrm{mg} /$ $\mathrm{dl}$ as a marker of tumour progression.

Table 2 Extent of Exposure: Number of cycles, treatment duration and total dose of BIBW 2992 (Safety Population)

\begin{tabular}{llll}
\hline Variable & $\begin{array}{l}\text { Dose level } 1 \\
(N=3)\end{array}$ & $\begin{array}{l}\text { Dose level }-1 \\
(N=6)\end{array}$ & $\begin{array}{l}\text { Total } \\
(N=9)\end{array}$ \\
\hline Number of cycles of chemotherapy & & \\
$N$ & 3 & 6 & 9 \\
Mean (SD) & $5.33(2.89)$ & $4.50(2.81)$ & $4.78(2.68)$ \\
Min & 2.0 & 2.0 & 2.0 \\
Median & 7.00 & 3.50 & 4.00 \\
Max & 7.0 & 8.0 & 8.0 \\
Missing & 0 & 0 & 0
\end{tabular}

Duration of BIBW Treatment [months]

$\begin{array}{llll}\text { N } & 3 & 6 & 9 \\ \text { Mean (SD) } & 4.0(2.5) & 3.3(2.3) & 3.6(2.2) \\ \text { Min } & 1.3 & 0.8 & 0.8 \\ \text { Median } & 4.4 & 2.7 & 3.3 \\ \text { Max } & 6.3 & 6.1 & 6.3 \\ \text { Missing } & 0 & 0 & 0\end{array}$

Total number of BIBW 2992 doses

\begin{tabular}{llll} 
N & 3 & 6 & 9 \\
Mean (SD) & $114.33(53.50)$ & $94.17(67.54)$ & $100.89(60.57)$ \\
Min & 54.0 & 9.0 & 9.0 \\
Median & 133.00 & 75.00 & 79.00 \\
Max & 156.0 & 179.0 & 179.0 \\
Missing & 0 & 0 & 0 \\
\hline
\end{tabular}




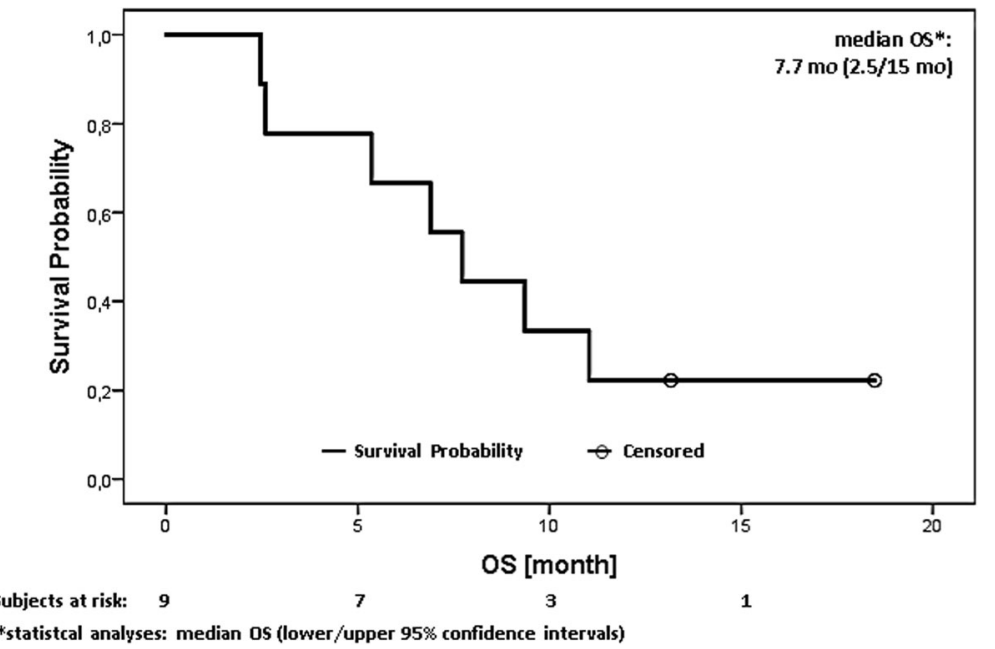

Fig. 1 Overall survival analysis in all patients under the combination of BIBW $2992+\mathrm{gem} / \mathrm{cis}$

\section{Safety and tolerability}

The proportion of patients experiencing treatmentrelated toxicities are shown in Table 3.

\section{Dose limiting toxicities}

All three patients in dose level 1 had at least one DLT during treatment. One patient showed hypokalaemia CTC grade III, whereas another had thrombocytopenia CTC grade IV, both during cycle 3 of treatment. The third patient experienced oral mucositis CTC grade III during cycle 1 as well as hypomagnesiaemia CTC grade III and thrombocytopenia CTC grade IV during cycle 2 of treatment.

Only one of six patients in dose level - 1 had DLTs. This patient experienced diarrhoea CTC grade III longer than 7 days and thrombocytopenia CTC grade IV during cycle 2 as well as thrombocytopenia and sepsis both CTC grad IV during cycle 3 of treatment.

\section{Serious adverse events (SAEs)}

In total, 14 SAEs were reported in all patients. The most common among them were infections, pulmonary embolism, diarrhoea as well as haematological disorders such as anaemia worsening.

\section{Adverse events}

The most frequent $\mathrm{AE}$ in dose levels 1 and -1 , respectively, were fatigue ( $3 / 6 \mathrm{pts})$, nausea ( $3 / 5 \mathrm{pts})$, diarrhoea ( $2 /$ $5 \mathrm{pts})$, rash (3/4 pts), stomatitis (3/4 pts), anaemia (3/3 pts), weight loss (1/6 pts), epistaxis ( $3 / 2 \mathrm{pts})$, neutropenia (2/3 pts), thrombocytopenia (2/3 pts), hypokalaemia ( $2 / 3$ pts), paraesthesia (1/4 pts) and paronychia ( $1 / 4 \mathrm{pts})$.

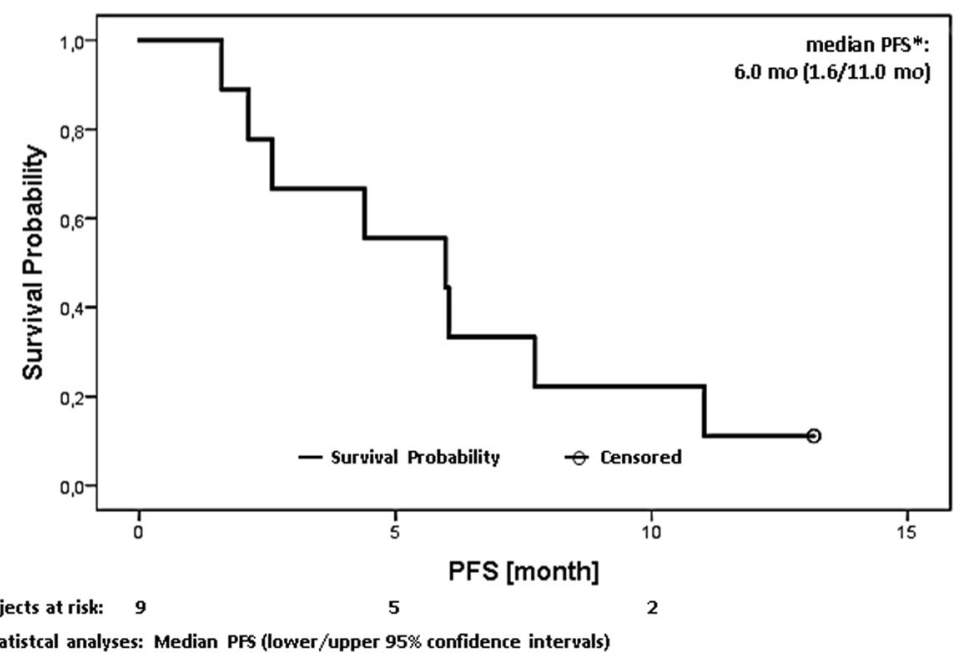

Fig. 2 Progression free survival analysis in all patients under the combination of BIBW $2992+\mathrm{gem} / \mathrm{cis}$ 
Table 3 Adverse Events (Safety Population)

\begin{tabular}{|c|c|c|c|c|c|c|c|c|c|}
\hline & Dose lev & & & Dose lev & & & Total & & \\
\hline Number of Patients with... & $(N=3)$ & & nEvents & $(N=6)$ & & nEvents & $(N=9)$ & & nEvents \\
\hline at least one $\mathrm{AE}$ & 3 & $(100.00 \%)$ & 141 & 6 & $(100.00 \%)$ & 247 & 9 & (100.00\%) & 388 \\
\hline SAEs & 2 & $(66.67 \%)$ & 6 & 5 & (83.33\%) & 13 & 7 & $(77.78 \%)$ & 19 \\
\hline Related AEs & 3 & (100.00\%) & 102 & 6 & (100.00\%) & 137 & 9 & (100.00\%) & 239 \\
\hline $\begin{array}{l}\text { AEs leading to premature } \\
\text { study discontinuation }\end{array}$ & 0 & $(0.00 \%)$ & 0 & 1 & $(16.67 \%)$ & 1 & 1 & (11.11\%) & 1 \\
\hline AEs leading to death & 1 & $(33.33 \%)$ & 2 & 1 & $(16.67 \%)$ & 1 & 2 & (22.22\%) & 3 \\
\hline
\end{tabular}

The most frequent Grade $3 / 4$ events (total $\geq 3$ ) were neutropenia ( $2 / 3 \mathrm{pts})$, anaemia ( $3 / 1 \mathrm{pts})$, thrombocytopenia ( $2 /$ 2 pts), diarrhoea (0/3pts) and hypokalaemia (2/1 pts).

\section{Translational analysis}

\section{Immunohistochemical staining}

Almost all patients $(7 / 8,88 \%)$ had an overexpression of EGFR on their tumour tissues. The expression of other receptors of the ErbB family (HER2neu, HER3 and HER4) was negative in the majority of the tissue samples (Fig. 3) (three patients showed weak HER2neu, two HER3 and four HER4 membrane staining). There was no correlation for the co-expression of these receptors.

\section{Mutational analysis of EGFR by sequencing}

The evaluable material (7/9) showed no known EGFR mutations in Exon 18, 19 or 21 in the cohort of afatinib patients.

\section{Serum analysis for angiogenesis and other biomarkers}

Based on the mOS, patients were subdivided in 2 groups: responders with OS $>7.5$ momths (4/9) and non-responders with OS $\leq 7.5$ months (5/9).

At the beginning of the therapy, responders had a lower medium serum level of VEGF-C, -D and sEGFR than non-responders. Patients with high leptin serum levels at the start of treatment showed a better response than patients with lower leptin levels. (Fig. 4 a-d).

During therapy (from cycle 1 to cycle 2), responders demonstrated a decrease of VEGF-C, $-\mathrm{D}$ and leptinlevels and an increase of sEGFR compared to nonresponders (Fig. 4 e-h). Patients with low sEGFR showed a better PFS and OS $(p=0.003)$ than patients with high serum sEGFR (data not shown).

The other examined serum markers showed no correlation with survival (data not shown).

\section{Discussion}

The majority of patients with CCA presents with unresectable disease [19] and their prognosis remains poor. Although chemotherapy has proved beneficial in controlling disease, OS rates of $\geq 10$ months are difficult to achieve, even with triple combinations [20]. Under treatment with cisplatin and gemcitabine, the current standard of care, patients with locally advanced or metastatic disease achieve OS and PFS of 11.7 months and 8 months respectively $[7,21]$. Therefore, the focus of recent and current studies remains the identification of a superior treatment combination while minimizing toxicity.
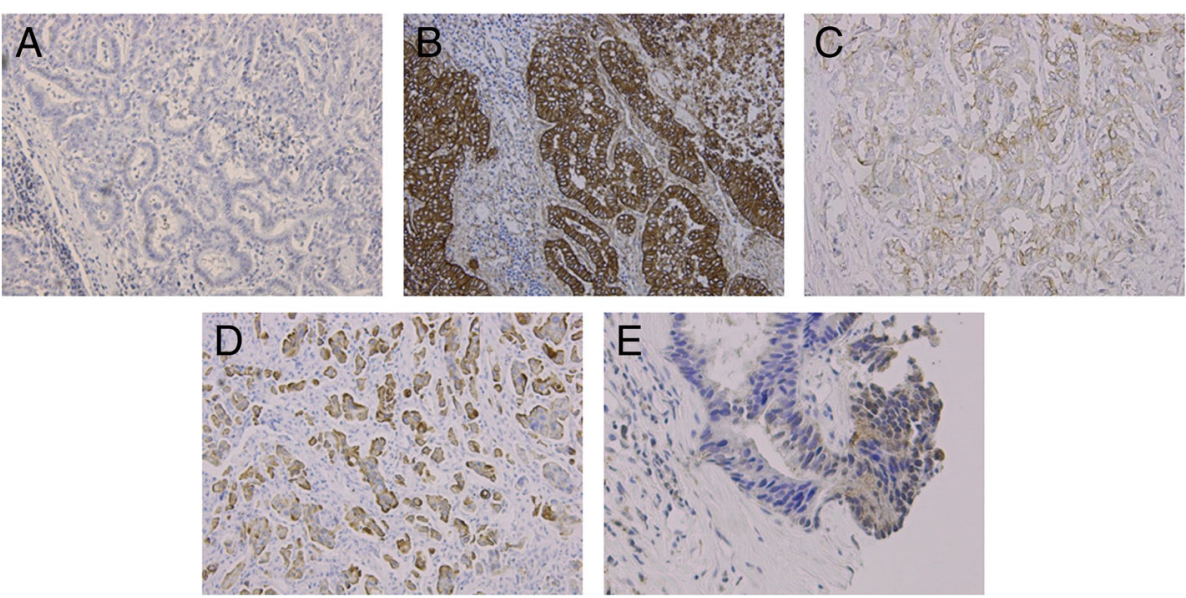

Fig. 3 Immunohistochemical staining, a) negative control, positive staining of b) EGFR (3+), c) HER2neu (1+), d) HER3 (2+) and e) HER4 (only sporadic) 

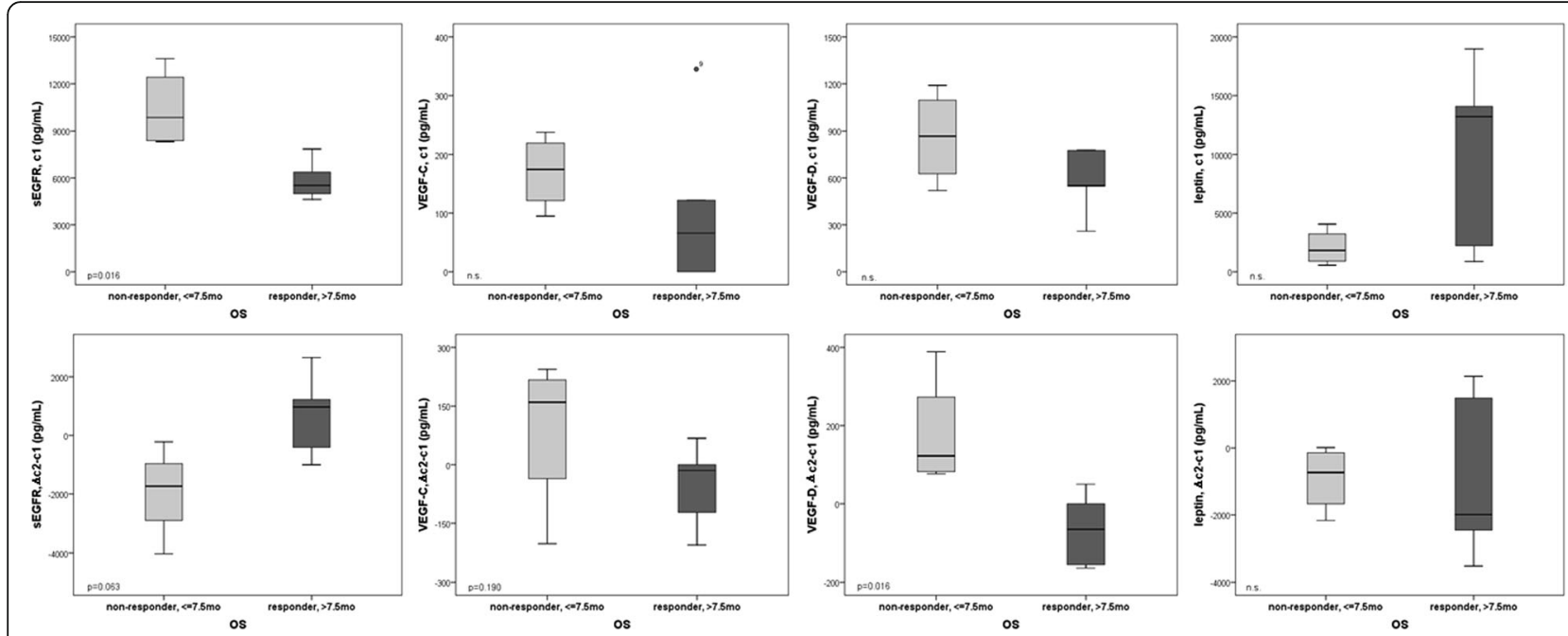

Fig. 4 sEGFR, VEGF-C, VEGF-D and leptin serum analysis of non-responders ( $n=4)$ OS $<=7.5$ months and responders $(n=5)$ OS $>7.5$ months. Circulated sEGFR, VEGF-C, VEGF-D and leptin levels at baseline (a-d). Median changes from the first to the second cycle of treatment of the described markers (e-h). Mann-Whitney- $U$ test $p<0.05$ is determined as significant. n.s. not significant

Prospective randomized studies examined the efficacy of single targeted therapies in advanced CCA similarly to treatment strategies for colorectal and gastric cancer. Despite initial encouraging reports [22] the addition of EGFR-inhibiting antibodies such as cetuximab or panitumumab to standard chemotherapy showed no survival benefits in recent randomized trials [23, 24]. Similar results were observed when TKIs targeting VEGF (sorafenib, cediranib) were added to gemcitabine and gemcitabine/cisplatin, respectively $[25,26]$. Furthermore, the addition of the TKI erlotinib to gemcitabine and oxaliplatin failed to reach the primary endpoint in a phase III Korean clinical trial [27].

In this phase I study, the panErbB inhibitor afatinib was tested as an add-on to gem/cis in patients with advanced CCA. Administration of $30 \mathrm{mg}$ afatinib on a daily basis was safely combined with a $20 \%$ reduced dose of standard gem/cis. Thus, dose level -1 was defined as MTD and recommended as dose level. This dose reduction seemed to be a rational approach, although $40 \mathrm{mg} / \mathrm{d}$ afatinib have already been approved by FDA and EMA for the treatment of NSCLC $[13,28]$. However in these cases, afatinib was being administered as monotherapy and not as an add-on to an already potentially toxic regimen such as gem/cis.

In our trial, the most frequent grade $3 / 4$ events were neutropenia, anaemia, thrombocytopenia, diarrhoea and hypokalaemia. Diarrhoea is a common side effect of afatinib already described in the Lux-lung trials [29-31]. The hematologic alterations observed in our study are most likely attributed to the backbone chemotherapy rather than to afatinib itself.
Regarding response to treatment, 63\% (5/9) of all evaluable patients showed tumour control for more than 4 months, and four patients achieved stable disease at end of treatment. However, the observed mOS and mPFS (Fig. 1 and Fig. 2) in our study were lower compared with previous key studies [7, 21]. A possible explanation for this reduced anti-tumour activity is that the patient majority received a reduced gem/cis treatment at dose level - 1 in order to avoid cumulative toxicity.

Further analyses in NSCLC revealed that the anti-tumour activity of afatinib is even higher in patients with EGFR mutations in exons 18, 19 and 21 [32, 33]. Although almost all of the patients in our study showed an overexpression of EGFR (Fig. 3) on their tumour tissues, none of the samples in our cohort revealed any of these favourable mutations. These results are in accordance with those published for NSCLC [32, 33]. Although CCA is characterized by different tumour biology, EGFR mutation analysis might be of importance for the choice of therapeutic treatment.

The reports concerning efficacy of ErbB family inhibitors in CCA have so far been restricted to cancer cell lines [34]. Nevertheless, the potential anti-tumour activity of ErbB family inhibition in patients with solid tumours has been at the focus of interest: Dacomitinib and HKI272 are the two most promising drugs that have reached phase III trials in patients with EGFR-mutated NSCLC and HER2neu positive breast cancer, respectively $[35,36]$. Dacomitinib has shown superiority over gefitinib as first line treatment in NSCLC patients with Exon 19 or Leu858Arg mutation of EGFR, regarding PFS in the multicenter ARCHER 1050 trial [35]. 
However, the results concerning OS were inconclusive at data cut off.

Finally, we performed a subgroup analysis with the aim of identifying potentially predictive biomarkers for the treatment with afatinib. As shown in Fig. 4, responders in terms of OS demonstrated lower levels of sEGFR as well as an increase of sEGFR during the first 2 cycles of treatment compared to non-responders. Similar results concerning the potential predictive role of circulated EGFR have been demonstrated in a phase II study with locally advanced esophagogastric cancer [37] as well as in a cohort of 102 NSCLC patients receiving an anti-EGFR therapy [38].

In the case of leptin, we observed an increase of serum levels in patients with no response to afatinib. Leptin has already been associated with the development of CCA through a STAT-3 dependent activation of ERK1/2 [39] and with the development of HCC through angiogenesis [40]. In gastric cancer, leptin induces tyrosine phosphorylation of EGFR resulting in transactivation of this cascade [41]. Our results suggest a complex involvement of leptin in carcinogenesis possibly via crosslinking of different pathways.

Furthermore, the analysis of patient sera in our study showed higher fluctuation of VEGF-C and -D (Fig. 4) but not of VEGF-A (data not shown) between responders and non-responders. These results are in accordance with those of a previously reported phase II trial [42]. In this multicenter study, the addition of bevacizumab to gem/cis did not improve survival compared with historical controls. On the other hand, other studies $[43,44]$ highlighted the significance of VEGF-C as a prognostic factor in patients with advanced biliary cancer most probably via cross-linking with the nuclear factor (NF)-kB pathway [45].

The limitation of our study is the small number of included patients, since the study was primarily designed to find the MDT and DLTs of afatinib. However, our data do not support the combination treatment of afatinib with gem/cis for advanced CCA as no sufficient clinical or molecular signals for efficacy and subgrouping for treatment selection were observed. Due to the potential inefficacy of EGFR targeting in biliary cancer the sponsor decided not to initiate the originally planned part B and further recruitment of patients in the current trial was discontinued.

\section{Conclusions}

The failure of conventional targeted therapies to improve survival rates in patients with advanced CCA underline the diversity of biliary cancer compared to the rest of gastrointestinal tumours. In this study the ErbB family inhibitor afatinib was safely administered as add-on to $80 \%$ of standard dose gemcitabine/cisplatin, but did not show any obvious survival benefits in a small number of patients with advanced CCA. However, the results of recent studies in patients with solid tumours suggest detailed molecular analysis for the identification of a particular group that may benefit from panHer inhibition. In this context, EGFR mutations might play a significant role for treatment stratification similar to NSCLC. Furthermore, other pathways associated with VEGF-C, -D, leptin and sEGFR may play a role in the therapeutic approach to advanced biliary cancer. Nevertheless, further studies are required to investigate the potential of these biomarkers in patients with advanced CCA.

\section{Additional files}

Additional file 1: Table S1. Main inclusion and exclusion criteria. Contains the main inclusion and exclusion criteria for patient selection in this study. (DOC $35 \mathrm{~kb}$ )

Additional file 2: Table S2. Predefined disease limited toxicities. List with the disease limited toxicities associated with afatinib in this study. (DOC $36 \mathrm{~kb}$ )

\section{Abbreviations \\ (s)EGFR, ErbB: (soluble) Epidermal growth factor receptor; EGF: Epidermal growth factor; FGF: Fibroblast growth factor; GITR: Glucocorticoid-induced TNFR-related protein; HER: Human epidermal growth factor receptor; HGF: Hepatocyte growth factor; HIF1a: Hypoxia-inducible factor 1-alpha; LAG-3: Lymphocyte-activation gene; MAPK: Mitogen-activated protein kinase; PD-L1: Programmed death-ligand 1; PI3KJAKT: Phosphoinositide 3-kinase / Protein kinase B; SDF-1a: Stromal cell-derived factor 1 alpha; STAT: Signal transducer and activator of transcription; VEGF: Vascular endothelial growth factor}

\section{Acknowledgements}

The authors are grateful to Ms. Thea Baetz and Ms. Sibylle Neufang for their contribution in patients' recruitment and organization of the study. We would also like to thank Ms. Heike Zimmer-Zachmann for her assistance in the preparation of the slides and the molecular analysis of patients' tumour tissues.

\section{Funding}

The project as investigator-initiated trial was primarily supported by the Mainz University clinic and supported by a minor grant of Boehringer Ingelheim, Germany for monitoring and translational research, as well as drug supply to M Moehler, K Goepfert and P. Galle. Thus, the design of the study and collection, analysis, and interpretation of data and writing of the manuscript was fully independent from Boehringer Ingelheim as a clear scientific project.

\section{Availability of data and materials}

The datasets used and/or analysed during the current study are available from the corresponding author on reasonable request.

\footnotetext{
Authors' contributions

MM: study concept and design, patient recruitment, drafting of the manuscript, critical revision of the manuscript, study supervision, AM: acquisition of data, analysis and interpretation of data, critical revision of the manuscript. AE, AS: acquisition of data, analysis and interpretation of data, TN, CR: technical or material support, statistical analysis, FF, AW: patient's recruitment, technical or material support. VS, JM: patients' recruitment, critical revision of the manuscript, PR.G: critical revision of the manuscript, administrative support, study supervision, MW: study concept and design, patients' recruitment, $\Pi$ : acquisition of data, analysis and interpretation of data, drafting of the manuscript, critical revision of the manuscript. All the authors critically reviewed and approved the manuscript.
} 


\section{Ethics approval and consent to participate}

The study was performed in accordance with the provisions of the Declaration of Helsinki, International Conference on Harmonisation, and Good Clinical Practice guidelines (NCT01679405). All patients provided written informed consent before enrolment. The study was approved by the ethic committee of the "Landesärztekammer Rheinland-Pfalz" Reference number: 837.541 .11 (8083)

\section{Consent for publication}

Not applicable

\section{Competing interests}

M.M is an associate Editor of BMC Cancer. The authors have otherwise no competing interests to declare.

\section{Publisher's Note}

Springer Nature remains neutral with regard to jurisdictional claims in published maps and institutional affiliations.

\begin{abstract}
Author details
'I. Medical Department, Johannes-Gutenberg University, Mainz, Germany. ${ }^{2}$ Interdisciplinary Center for Clinical Trials, Johannes-Gutenberg University of Mainz, Mainz, Germany. ${ }^{3}$ Department of Pathology, Johannes-Gutenberg University, Mainz, Germany. ${ }^{4}$ First Department of Medicine, University Medical Center of the Johannes-Gutenberg University Mainz, Langenbeckstr. 1, 55131 Mainz, Germany.
\end{abstract}

Received: 5 May 2018 Accepted: 13 December 2018 Published online: 11 January 2019

\section{References}

1. Jarnagin WR, Fong Y, DeMatteo RP, Gonen M, Burke EC, Bodniewicz BJ, Youssef BM, Klimstra D, Blumgart LH. Staging, resectability, and outcome in 225 patients with hilar cholangiocarcinoma. Ann Surg. 2001;234(4):507-17 discussion 517-509.

2. Malka D, Dromain C, Landi B, Prat F, De Baere T, Delpero JR, Chiche L: Cancers of the biliary system. Gastroenterol Clin Biol. 2006;30 Spec No 2 2S62-62S74

3. Kubicka S. Cholangiocellular and gallbladder carcinoma. Z Gastroenterol. 2004:42(5):397-402.

4. Puhalla H, Schuell B, Pokorny H, Kornek GV, Scheithauer W, Gruenberger T. Treatment and outcome of intrahepatic cholangiocellular carcinoma. Am J Surg. 2005;189(2):173-7.

5. Malik IA. Gallbladder cancer: current status. Expert Opin Pharmacother. 2004; 5(6):1271-7.

6. Lazaridis KN, Gores GJ. Cholangiocarcinoma. Gastroenterology. 2005;128(6): 1655-67.

7. Valle J, Wasan H, Palmer DH, Cunningham D, Anthoney A, Maraveyas A, Madhusudan S, Iveson T, Hughes S, Pereira SP, Roughton M, Bridgewater J. Cisplatin plus gemcitabine versus gemcitabine for biliary tract cancer. N Engl J Med. 2010;362(14):1273-81.

8. Scaltriti M, Baselga J. The epidermal growth factor receptor pathway: a model for targeted therapy. Clin Cancer Res. 2006;12(18):5268-72.

9. Ono M, Kuwano M. Molecular mechanisms of epidermal growth facto receptor (EGFR) activation and response to gefitinib and other EGFRtargeting drugs. Clin Cancer Res. 2006;12(24):7242-51.

10. Soria JC, Cortes J, Massard C, Armand JP, De Andreis D, Ropert S, Lopez E, Catteau A, James J, Marier JF, Beliveau M, Martell RE, Baselga J. Phase safety, pharmacokinetic and pharmacodynamic trial of BMS-599626 (AC480), an oral pan-HER receptor tyrosine kinase inhibitor, in patients with advanced solid tumors. Ann Oncol. 2012;23(2):463-71.

11. Kim T, LeeK W, OhD Y. A phase I study of HM781-36B, a novel pan-HER inhibitor,in patients (with advanced solid tumors). J Clin Oncol. 2012;30: 3076.

12. Ramalingam SS, Blackhall F, Krzakowski M, Barrios CH, Park K, Bover I, Seog Heo D, Rosell R, Talbot DC, Frank R, Letrent SP, Ruiz-Garcia A, Taylor I, Liang JQ, Campbell AK, O'Connell J, Boyer M. Randomized phase II study of dacomitinib (PF-00299804), an irreversible pan-human epidermal growth factor receptor inhibitor, versus erlotinib in patients with advanced nonsmall-cell lung cancer. J Clin Oncol. 2012;30(27):3337-44.
13. Sequist LV, Yang JC, Yamamoto N, O'Byrne K, Hirsh V, Mok T, Geater SL, Orlov S, Tsai CM, Boyer M, Su WC, Bennouna J, Kato T, Gorbunova V, Lee $\mathrm{KH}$, Shah R, Massey D, Zazulina V, Shahidi M, Schuler M. Phase III study of afatinib or cisplatin plus pemetrexed in patients with metastatic lung adenocarcinoma with EGFR mutations. J Clin Oncol. 2013;31(27):3327-34.

14. Vermorken JB, Rottey S, Ehrnrooth E, Pelling K, Lahogue A, Wind S, Machiels JP. A phase Ib, open-label study to assess the safety of continuous oral treatment with afatinib in combination with two chemotherapy regimens: cisplatin plus paclitaxel and cisplatin plus 5-fluorouracil, in patients with advanced solid tumors. Ann Oncol. 2013;24(5):1392-400.

15. Ioannou N, Dalgleish AG, Seddon AM, Mackintosh D, Guertler U, Solca F, Modjtahedi H. Anti-tumour activity of afatinib, an irreversible ErbB family blocker, in human pancreatic tumour cells. Br J Cancer. 2011;105(10): 1554-62.

16. Eskens FA, Mom CH, Planting AS, Gietema JA, Amelsberg A, Huisman $\mathrm{H}$, van Doorn L, Burger H, Stopfer P, Verweij J, de Vries EG. A phase I dose escalation study of BIBW 2992, an irreversible dual inhibitor of epidermal growth factor receptor 1 (EGFR) and 2 (HER2) tyrosine kinase in a 2-week on, 2-week off schedule in patients with advanced solid tumours. $\mathrm{Br} \mathrm{J}$ Cancer. 2008;98(1):80-5.

17. Yap TA, Vidal L, Adam J, Stephens P, Spicer J, Shaw H, Ang J, Temple G, Bell S, Shahidi M, Uttenreuther-Fischer M, Stopfer P, Futreal A, Calvert H, de Bono JS, Plummer R. Phase I trial of the irreversible EGFR and HER2 kinase inhibitor BIBW 2992 in patients with advanced solid tumors. J Clin Oncol. 2010;28(25):3965-72.

18. Eisenhauer EA, Therasse $P$, Bogaerts J, Schwartz LH, Sargent D, Ford R, Dancey J, Arbuck S, Gwyther S, Mooney M, Rubinstein L, Shankar L, Dodd L, Kaplan R, Lacombe D, Verweij J. New response evaluation criteria in solid tumours: revised RECIST guideline (version 1.1). Eur J Cancer. 2009;45(2): 228-47.

19. Klebl F, Endlicher E, Kullmann F. Palliative therapy in cholangio- and gallbladder carcinoma. Z Gastroenterol. 2006:44(7):587-98.

20. Wagner AD, Buechner-Steudel $P$, Moehler M, Schmalenberg $H$, Behrens $R$, Fahlke J, Wein A, Behl S, Kuss O, Kleber G, Fleig WE. Gemcitabine, oxaliplatin and 5-FU in advanced bile duct and gallbladder carcinoma: two parallel, multicentre phase-II trials. Br J Cancer. 2009;101(11):1846-52.

21. Okusaka T, Nakachi K, Fukutomi A, Mizuno N, Ohkawa S, Funakoshi A, Nagino M, Kondo S, Nagaoka S, Funai J, Koshiji M, Nambu Y, Furuse J, Miyazaki M, Nimura Y. Gemcitabine alone or in combination with cisplatin in patients with biliary tract cancer: a comparative multicentre study in Japan. Br J Cancer. 2010;103(4):469-74.

22. Sprinzl MF, Schimanski CC, Moehler M, Schadmand-Fischer S, Galle PR, Kanzler S. Gemcitabine in combination with EGF-receptor antibody (Cetuximab) as a treatment of cholangiocarcinoma: a case report. BMC Cancer. 2006;6:190.

23. Malka D, Cervera P, Foulon S, Trarbach T, de la Fouchardiere C, Boucher E, Fartoux L, Faivre S, Blanc JF, Viret F, Assenat E, Seufferlein T, Herrmann T, Grenier J, Hammel P, Dollinger M, Andre T, Hahn P, Heinemann V, Rousseau $V$, Ducreux M, Pignon JP, Wendum D, Rosmorduc O, Greten TF. Gemcitabine and oxaliplatin with or without cetuximab in advanced biliarytract cancer (BINGO): a randomised, open-label, non-comparative phase 2 trial. Lancet Oncol. 2014;15(8):819-28.

24. Leone F, Marino D, Cereda S, Filippi R, Belli C, Spadi R, Nasti G, Montano M, Amatu A, Aprile G, Cagnazzo C, Fasola G, Siena S, Ciuffreda L, Reni M, Aglietta M. Panitumumab in combination with gemcitabine and oxaliplatin does not prolong survival in wild-type KRAS advanced biliary tract cancer: a randomized phase 2 trial (Vecti-BIL study). Cancer. 2016;122(4):574-81.

25. Moehler M, Maderer A, Schimanski C, Kanzler S, Denzer U, Kolligs FT, Ebert MP, Distelrath A, Geissler M, Trojan J, Schutz M, Berie L, Sauvigny C, Lammert F, Lohse A, Dollinger MM, Lindig U, Duerr EM, Lubomierski N, Zimmermann S, Wachtlin D, Kaiser AK, Schadmand-Fischer S, Galle PR, Woerns M. Gemcitabine plus sorafenib versus gemcitabine alone in advanced biliary tract cancer: a double-blind placebo-controlled multicentre phase II AIO study with biomarker and serum programme. Eur J Cancer. 2014;50(18):3125-35

26. Valle JW, Wasan H, Lopes A, Backen AC, Palmer DH, Morris K, Duggan M, Cunningham D, Anthoney DA, Corrie P, Madhusudan S, Maraveyas A, Ross PJ, Waters JS, Steward WP, Rees C, Beare S, Dive C, Bridgewater JA. Cediranib or placebo in combination with cisplatin and gemcitabine chemotherapy for patients with advanced biliary tract cancer (ABC-03): a randomised phase 2 trial. Lancet Oncol. 2015;16(8):967-78. 
27. Lee J, Park SH, Chang HM, Kim JS, Choi HJ, Lee MA, Jang JS, Jeung HC, Kang JH, Lee HW, Shin DB, Kang HJ, Sun JM, Park JO, Park YS, Kang WK, Lim HY. Gemcitabine and oxaliplatin with or without erlotinib in advanced biliary-tract cancer: a multicentre, open-label, randomised, phase 3 study. Lancet Oncol. 2012;13(2):181-8

28. Wu YL, Zhou C, Hu CP, Feng J, Lu S, Huang Y, Li W, Hou M, Shi JH, Lee KY, Xu CR, Massey D, Kim M, Shi Y, Geater SL. Afatinib versus cisplatin plus gemcitabine for first-line treatment of Asian patients with advanced nonsmall-cell lung cancer harbouring EGFR mutations (LUX-lung 6): an openlabel, randomised phase 3 trial. Lancet Oncol. 2014;15(2):213-22.

29. Yang JC, Shih JY, Su WC, Hsia TC, Tsai CM, Ou SH, Yu CJ, Chang GC, Ho CL Sequist LV, Dudek AZ, Shahidi M, Cong XJ, Lorence RM, Yang PC, Miller VA Afatinib for patients with lung adenocarcinoma and epidermal growth factor receptor mutations (LUX-lung 2): a phase 2 trial. Lancet Oncol. 2012; 13(5):539-48.

30. Schuler M, Yang JC, Park K, Kim JH, Bennouna J, Chen YM, Chouaid C, De Marinis F, Feng JF, Grossi F, Kim DW, Liu X, Lu S, Strausz J, Vinnyk Y, Wiewrodt R, Zhou C, Wang B, Chand VK, Planchard D. Afatinib beyond progression in patients with non-small-cell lung cancer following chemotherapy, erlotinib/gefitinib and afatinib: phase III randomized LUXlung 5 trial. Ann Oncol. 2016;27(3):417-23.

31. Park K, Tan EH, O'Byrne K, Zhang L, Boyer M, Mok T, Hirsh V, Yang JC, Lee KH, Lu S, Shi Y, Kim SW, Laskin J, Kim DW, Arvis CD, Kolbeck K, Laurie SA, Tsai CM, Shahidi M, Kim M, Massey D, Zazulina V, Paz-Ares L. Afatinib versus gefitinib as first-line treatment of patients with EGFR mutation-positive nonsmall-cell lung cancer (LUX-lung 7): a phase 2B, open-label, randomised controlled trial. Lancet Oncol. 2016;17(5):577-89.

32. Kobayashi $Y$, Togashi $Y$, Yatabe $Y$, Mizuuchi $H$, Jangchul $P$, Kondo C, Shimoji M, Sato K, Suda K, Tomizawa K, Takemoto T, Hida T, Nishio K, Mitsudomi T. EGFR exon 18 mutations in lung Cancer: molecular predictors of augmented sensitivity to Afatinib or Neratinib as compared with first- or third-generation TKIs. Clin Cancer Res. 2015;21(23):5305-13.

33. Yang JC, Wu YL, Schuler M, Sebastian M, Popat S, Yamamoto N, Zhou C, Hu CP, O'Byrne K, Feng J, Lu S, Huang Y, Geater SL, Lee KY, Tsai CM, Gorbunova V, Hirsh V, Bennouna J, Orlov S, Mok T, Boyer M, Su WC, Lee KH, Kato T, Massey D, Shahidi M, Zazulina V, Sequist LV. Afatinib versus cisplatin-based chemotherapy for EGFR mutation-positive lung adenocarcinoma (LUX-lung 3 and LUX-lung 6): analysis of overall survival data from two randomised, phase 3 trials. Lancet Oncol. 2015;16(2):141-51.

34. Nam HJ, Kim HP, Yoon YK, Song SH, Min AR, Han SW, Im SA, Kim TY, Oh DY, Bang YJ. The irreversible pan-HER inhibitor PF00299804 alone or combined with gemcitabine has an antitumor effect in biliary tract cancer cell lines. Investig New Drugs. 2012;30(6):2148-60

35. Wu YL, Cheng Y, Zhou X, Lee KH, Nakagawa K, Niho S, Tsuji F, Linke R, Rosell R, Corral J, Migliorino MR, Pluzanski A, Sbar El, Wang T, White JL, Nadanaciva S, Sandin R, Mok TS. Dacomitinib versus gefitinib as first-line treatment for patients with EGFR-mutation-positive non-small-cell lung cancer (ARCHER 1050): a randomised, open-label, phase 3 trial. Lancet Oncol. 2017;18(11):1454-66.

36. Martin M, Holmes FA, Ejlertsen B, Delaloge S, Moy B, Iwata H, von Minckwitz G, Chia SKL, Mansi J, Barrios CH, Gnant M, Tomasevic Z, Denduluri N, Separovic R, Gokmen E, Bashford A, Ruiz Borrego M, Kim SB, Jakobsen EH, Ciceniene A, Inoue K, Overkamp F, Heijns JB, Armstrong AC, Link JS, Joy AA, Bryce R, Wong A, Moran S, Yao B, Xu F, Auerbach A, Buyse M, Chan A. Neratinib after trastuzumab-based adjuvant therapy in HER2-positive breast cancer (ExteNET): 5-year analysis of a randomised, double-blind, placebocontrolled, phase 3 trial. Lancet Oncol. 2017;18(12):1688-700.

37. Stahl M, Maderer A, Lordick F, Mihaljevic AL, Kanzler $S$, Hoehler $T$, ThussPatience P, Monig S, Kunzmann V, Schroll S, Sandermann A, Tannapfel A, Meyer HJ, Schuhmacher C, Wilke H, Moehler M. Perioperative chemotherapy with or without epidermal growth factor receptor blockade in unselected patients with locally advanced oesophagogastric adenocarcinoma: randomized phase II study with advanced biomarker program of the German Cancer society (AIO/CAO STO-0801). Eur J Cancer. 2018;93:119-26.

38. Kappers I, Vollebergh MA, van Tinteren H, Korse CM, Nieuwenhuis LL, Bonfrer JM, Klomp HM, van Zandwijk N, van den Heuvel MM. Soluble epidermal growth factor receptor (sEGFR) and carcinoembryonic antigen (CEA) concentration in patients with non-small cell lung cancer: correlation with survival after erlotinib and gefitinib treatment. Ecancermedicalscience. 2010;4:178.
39. Fava G, Alpini G, Rychlicki C, Saccomanno S, DeMorrow S, Trozzi L, Candelaresi C, Venter J, Di Sario A, Marzioni M, Bearzi I, Glaser S, Alvaro D, Marucci L, Francis H, Svegliati-Baroni G, Benedetti A. Leptin enhances cholangiocarcinoma cell growth. Cancer Res. 2008;68(16):6752-61.

40. Ribatti D, Belloni AS, Nico B, Di Comite M, Crivellato E, Vacca A. Leptin-leptin receptor are involved in angiogenesis in human hepatocellular carcinoma. Peptides. 2008;29(9):1596-602.

41. Shida D, Kitayama J, Mori K, Watanabe T, Nagawa H. Transactivation of epidermal growth factor receptor is involved in leptin-induced activation of janus-activated kinase 2 and extracellular signal-regulated kinase 1/2 in human gastric cancer cells. Cancer Res. 2005;65(20):9159-63.

42. Iyer RV, Pokuri VK, Groman A, Ma WW, Malhotra U, lancu DM, Grande C, Saab TB: A Multicenter Phase II. Study of gemcitabine, Capecitabine, and bevacizumab for locally advanced or metastatic biliary tract Cancer. Am J Clin Oncol. 2016 Am J Clin Oncol. 2018;41(7):649-655. https://doi.org/10. 1097/COC.0000000000000347.

43. Park BK, Paik YH, Park JY, Park KH, Bang S, Park SW, Chung JB, Park YN, Song SY. The clinicopathologic significance of the expression of vascular endothelial growth factor-C in intrahepatic cholangiocarcinoma. Am J Clin Oncol. 2006;29(2):138-42.

44. Nakashima T, Kondoh S, Kitoh H, Ozawa H, Okita S, Harada T, Shiraishi K, Ryozawa S, Okita K. Vascular endothelial growth factor-C expression in human gallbladder cancer and its relationship to lymph node metastasis. Int J Mol Med. 2003;11(1):33-9.

45. Du Q, Jiang L, Wang X, Wang M, She F, Chen Y. Tumor necrosis factor-alpha promotes the lymphangiogenesis of gallbladder carcinoma through nuclear factor-kappaB-mediated upregulation of vascular endothelial growth factorC. Cancer Sci. 2014;105(10):1261-71.
Ready to submit your research? Choose BMC and benefit from:

- fast, convenient online submission

- thorough peer review by experienced researchers in your field

- rapid publication on acceptance

- support for research data, including large and complex data types

- gold Open Access which fosters wider collaboration and increased citations

- maximum visibility for your research: over $100 \mathrm{M}$ website views per year

At BMC, research is always in progress.

Learn more biomedcentral.com/submissions 